\title{
EL CAMPO RELIGIOSO \\ EN LOS ASENTAMIENTOS PRECARIOS DE BUENOS AIRES. UNA APROXIMACIÓN DESDE LA SITUACIÓN RELIGIOSA DE LAS MUJERES
}

\author{
Ana Lourdes Suárez
}

Resumen: El trabajo caracteriza la situación religiosa de las mujeres residentes en asentamientos precarios de Buenos Aires desde una aproximación cuantitativa. Se explora primero el abordaje conceptual de las capacidades destacando los recursos que brinda para un entendimiento innovador de la religión y de la religiosidad popular. Se presenta luego el universo de estudio, la fuente de datos utilizada -una encuesta producida en la UCA-, el abordaje metodológico, sus posibilidades y limitaciones. En tercer lugar se analiza la identidad, la práctica y la participación religiosa. Se analiza luego cómo la situación religiosa según los aspectos mencionados varía al cruzarlas con algunas dimensiones sociodemográficas: nivel de instrucción, edad, lugar de procedencia, y situación conyugal. Luego se explora la confianza en las instituciones y en actores religiosos. Se concluye con reflexiones que articulan el análisis efectuado con el marco teórico propuesto.

Palabras claves: Campo Religioso; Mujeres; Asentamientos precarios de Buenos Aires.

Abstract: The article addresses the religious situation of women living in Buenos Aires slums from a quantitative approach. It first explores the capability approach, highlighting the resources it provides for an innovative understanding of religion and popular religiosity. We then discuss the data used - a survey produced by an UCA research team -, and the possibilities and limitations of the methodological approach. On third place we analyze religious identity, practice, and participation. We then address how the religious situation varies according to some socio-demographic dimensions: education, age, marital and immigration situation. We finally address confidence in institutions and religious actors. The article concludes with reflections that articulate the analysis carried out with the theoretical framework.

Keywords: Religious Field; Women; Buenos Aires Slums.

1 Consejo Nacional de Investigaciones Científicas y Técnicas (CONICET) / Pontificia Universidad Católica Argentina (UCA). Buenos Aires, Argentina. Contacto: analourdessuarez@gmail.com.

Debates do NER, Porto Alegre, ANo I5, N. 25, P. 24I-270, JAn./Jun. 20 I4 


\section{INTRODUCCIÓN}

Los asentamientos precarios de la ciudad de Buenos Aires pese a la homogeneidad socioeconómica de su población, conforman un espacio de una gran diversidad y riqueza cultural. Diversidad que se nutre, entre otros aspectos, de la variedad de lugares de proveniencia de sus pobladores, en la habilidad de los habitantes para insertarse en una ciudad que en muchos aspectos se presenta como hostil, en la creatividad para orquestar la supervivencia cotidiana pese a las fuertes adversidades. Esta diversidad cultural se expresa en la religiosidad palpable en el espacio. Cualquiera que haga un recorrido rápido por los barrios precarios de la ciudad no puede dejar de notar la cantidad y variedad de marcas religiosas en el espacio público: imágenes de la Virgen en sus diversas advocaciones: Lujan, Caacupé, Copacabana, Urcupiña, etc.; cruces e inscripciones que indican la presencia de capillas cristianas (católicas o evangélicas); pequeños "santuarios" de santos (Cayetano, Francisco, etc.) que se entrecruzan con íconos populares de santidad como el Gauchito Gil, la Difunta Correa, etc. Son todas marcas que hablan de una religiosidad viva y presente en la vida cotidiana de las personas en estos barrios.

Dar cuenta de la variedad y riqueza de este espacio requiere de un estudio de caso en profundidad en el que se recurra a diversas fuentes de datos cuantitativos y cualitativos. El presente trabajo recurre solo a una fuente: la encuesta efectuada en el marco del Programa Organizaciones de la Sociedad Civil y Capacidades del Desarrollo Humano de la Universidad Católica Argentina (OSCDH-UCA), consciente que se trata sólo de una pequeña ventana a la situación religiosa, entre las muchas otras que deberían abrirse para mirar el campo religioso en este espacio urbano. El análisis se efectúa a sabiendas de las grandes limitaciones que supone adentrarse en este campo recurriendo solo a datos cuantitativos. Esta conciencia me lleva ser cauta en la caracterización propuesta y a contener mi deseo de avanzar con argumentaciones que los datos no permiten hacer. Cabe asimismo destacar que si bien la expresión "campo religioso" se ha convertido, en los textos de los especialistas, en una especie de "comodín lingüístico" que facilita la mención del fenómeno de la diversidad religiosa, sin por eso 
convertirse en un instrumento de análisis (Martínez, 2013, p. 91), lo utilizamos porque creemos que es de gran utilidad para iluminar dinámicas en contextos específicos como el que escogimos para este trabajo: asentamientos precarios. Espacio en el que puede observarse el flujo y la tensión entre las instituciones religiosas y las religiosidades que con frecuencia se desarrollan en sus márgenes. ${ }^{2}$

El esquema del trabajo es el siguiente: se presenta primero un breve marco conceptual desde el cual abordar el tema; se explora el abordaje de las capacidades destacando los recursos que brinda para un entendimiento innovador de la religión y de la religiosidad popular. Se presenta luego el universo de estudio, la fuente de datos utilizada, el abordaje metodológico, sus posibilidades y limitaciones. En tercer lugar se analiza la identidad, la práctica y la participación religiosa. En cuarto lugar se analiza cómo la situación religiosa según los aspectos mencionados varía al cruzarlas con algunas dimensiones sociodemográficas: nivel de instrucción, edad, lugar de procedencia y situación conyugal. Luego se explora la confianza en las instituciones y en actores religiosos del universo de estudio. El trabajo termina con conclusiones y algunas reflexiones.

\section{LA RELIGIÓN Y LA RELIGIOSIDAD POPULAR DESDE EL ABORDAJE DE LAS CAPACIDADES}

La antropología religiosa muestra que la religión comprende mucho más que la creencia en Dios o en la trascendencia. La religión es un espacio al que muchas personas recurren para entender el mundo y su lugar en él. La gente recurre a lo religioso para encontrar sentidos profundos a sus vidas, a sus problemas, a sus dolores y alegrías (Bradley, 2009). En la religión, entre otros aspectos, encuentran respuestas que la ciencia no puede dar, encuentran respuesta a las injusticias, hallan bases morales sobre las que juzgar los

2 Ana Teresa Martínez destaca la utilidad del concepto "campo religioso" para visibilizar el creciente quiebre de la hegemonía católica, la multiplicación de instituciones religiosas y de las religiosidades, así como para explicitar los espacios de no-creencia y de las heterodoxias radicales (Martínez, 2013, p. 99).

Debates do NER, Porto Alegre, ano I5, N. 25, P. 24I-270, Jan./Jun. 2014 
actos propios y de los demás. La dimensión religiosa es fundamental en la formulación de creencias espirituales y morales, que a su vez se traducen en relaciones sociales que afectan la vida de las personas.

El abordaje de las capacidades parte de esta constatación antropológica y da un marco innovador desde el cual pensar la religión. El eje central es el sujeto del que se destaca su libertad para llevar el tipo de vida que valora. Conceptos fundamentales del enfoque son los funcionamientos y las capacidades. Los funcionamientos/realizaciones, manifiestan "[...] las cosas que una persona puede valorar hacer o ser" (Sen, 2000, p. 99). "La capacidad de una persona se refiere a las diversas combinaciones de funciones que puede conseguir... es un tipo de libertad: la libertad fundamental para conseguir distintas combinaciones de funciones" (Sen, 2000, p. 99-100). Se trata de la libertad de elegir el estilo de vida que se quiere llevar.

La base del enfoque de las capacidades, particularmente en la formulación de Martha Nussbaum, es la naturaleza política del ser humano; un ser cuya socialidad no es una condena ni responde exclusivamente a razones de tipo pragmático, sino a una vocación de plenitud que se realiza, una vida que "florece" en el encuentro con el otro (Leal, 2012). Nussbaum, como señala Leal, se distancia del contractualismo clásico, abrazando un liberalismo que podría definirse como una síntesis entre personalismo y pluralismo. Se basa en una antropología que posee dos notas fundamentales: la fragilidad como condición humana básica ${ }^{3}$ y y la identidad plural de las personas. Es desde esa condición que las personas buscan llevar la vida que tienen razón de valorar.

3 Siguiendo a Leal (2012), Nussbaum (2002) entiende la 'fragilidad' en dos sentidos fundamentales. El primero está relacionado con nuestra existencia de seres corporales y necesitados, durante casi la totalidad de la vida, de cuidado y asistencia. El segundo tiene que ver con una dimensión interior; según Nussbaum, cada ser humano a lo largo de su vida se verá enfrentado a situaciones trágicas, es decir, momentos en que tendrá de frente a sí dos posibilidades, cada una de ellas buena y eventualmente justa, y estará obligado a tomar una decisión. En el acto de optar el hombre experimenta la renuncia, el dolor y, al mismo tiempo, la felicidad. El éxito de su decisión no está garantizado, y los ciegos embates de la fortuna están siempre al acecho, sin embargo, solo a través de este caminar el ser humano puede llegar a ser realmente aquello que es (Nussbaum, 2002, p. 256-261). Y es en estas encrucijadas donde se juega el sentido de la vida.

Debates do NER, Porto Alegre, ANo I5, N. 25, P. 24I-270, JAN./Jun. 2014 
La importancia de la religión, siguiendo a Nussbaum, radica en primer lugar en su relación con el derecho de cada persona a buscar el sentido de su propia vida y llevar la vida que valora. Las religiones son sistemas articulados dadores de sentido que alimentan asimismo las acciones de las personas. La autora señala, en base a este argumento, que al adentrarnos en las grandes tradiciones religiosas se constata que todas ellas han procurado estimular en sus miembros sentimientos como la compasión frente al sufrimiento humano y la solidaridad. Las diversas tradiciones religiosas son fuerzas vivas que proyectan ideales sociales, morales e intelectuales que sostienen las esperanzas y aspiraciones de las personas (Deneulin; Bado, 2009). Estas tradiciones religiosas que, como todas las tradiciones culturales son dinámicas y heterogéneas, desde esta perspectiva, son dadoras de "agencia" (agency) - otro concepto clave en el enfoque de las capacidades -; o sea son dadoras de la habilidad de luchar por objetivos que uno valora y tiene razón de valorar (Sen, 2000). Una persona con agencia es alguien que genera transformaciones.

Las diversas tradiciones religiosas de alguna manera sostienen y defienden una cierta idea de justicia (Nussbaum, 2002). De ahí, como afirma Leal (2012) la relevancia de la religión en la teorización de una ética pública. Es precisamente porque las religiones hablan de moral que son importantes políticamente hablando. Cabe así cuestionar el supuesto del discurso cotidiano que asume que la religión es un asunto privado (especialmente en los países de tradición cristiana). Las religiones hacen parte de la esfera pública, porque todas ellas tienen una preocupación ético-política. Un termómetro de la madurez de las religiones una vez en la esfera pública, es su capacidad de dar cuenta de su pluralidad interna, o sea de autocorrección. ${ }^{4}$

4 Claudia Leal (2012) resume dos criterios establecidos por Nussbaum (2002) que deben informar el rol público de las religiones. El primero de ellos es el principio de cada persona como fin, porque "toda solución que parezca buena para un grupo religioso deberá ser sometida a prueba para ver si promueve también las capacidades religiosas (junto a las otras capacidades) de los miembros del grupo tomados individualmente". En segundo lugar, nos propone el principio de la restricción moral, porque "rechazaríamos tener deferencia ante la religión cuando sus prácticas dañan a la gente en las áreas que cubren

Debates do NER, Porto Alegre, ano I5, N. 25, P. 24I-270, JAn./Jun. 2014 
En resumen, la religión es a menudo una parte significativa de la vida de las personas, que infunde lo que valoran, lo que son y lo que hacen. La religión tiene en la teoría de las capacidades un rol público y funcional, en el sentido que ella, en virtud de su gran impacto en la vida de las personas, adquiere relevancia en la medida que puede convertirse en una aliada de las capacidades. Sin embargo, no está nunca inmune al poder y está siempre enmarcada en la estructura social y económica (Deneulin, 2009b).

La perspectiva del abordaje de las capacidades sobre el rol de la religión en las sociedades, tiene afinidades con lecturas que valoran la religiosidad popular ${ }^{5}$ en tanto hacedora de cultura desde procesos históricos concretos. Las ciencias sociales hacen referencia a esta categoría de la religiosidad en relación al conjunto de creencias y prácticas de ciertos sectores más marginales (Ameigeiras, 2008; entre varios otros), lo cual le da una connotación peculiar a perspectivas académicas que la destacan y valoran. La religiosidad popular expresa la forma en que el pueblo a través de sus necesidades fundamentales cree en lo trascendente y lo busca. ${ }^{6}$ Las motivaciones humanas, cosmológicas, holísticas son expresiones de la forma que toma el vínculo con Dios. Las ritualidades, prácticas y devociones expresan este vínculo y a su vez canalizan una forma de ser, de estar y de transformar contextos (sean estos sociales, eclesiales, políticos, etc.). La cultura popular es algo dinámico; se moldea entre otras dimensiones, por las diversas formas de entender como lo sagrado, lo trascendente, interviene en la historia.

las capacidades mayores". Las capacidades centrales, en resumen, son intereses urgentes del Estado, y la violación de una de ellas justifica su intervención en nombre no solo de los intereses de el/los ciudadano(s) afectado(s), sino también de una auténtica religión.

5 El calificativo popular, hace referencia al pueblo; destaco la definición que dan de pueblo los teólogos afines a lo que en América Latina se conoce como Teología del Pueblo: "el pueblo es la realidad histórica de personas aunadas en la vivencia común de unos valores que conforman su cultura y su estilo de vida" (Albado, 2013).

6 En los sectores populares suelen convivir prácticas y discursos ligados a lo religioso que tienen orígenes muy diversos. Gran parte de ellos son originarios de instituciones religiosas pertenecientes a las grandes tradiciones históricas - en Argentina, principalmente el catolicismo pero cada vez con más fuerza el pentecostalismo -, coexistiendo con prácticas y creencias 'locales' - muchas veces relocalizadas y florecidas lejos de su zona de origen (López Fidanza; Galera, 2012).

Debates do NER, Porto Alegre, ano I5, N. 25, P. 24I-270, Jan./Jun. 2014 
Así, el cruce entre cultura popular y proceso histórico permite captar los cauces por donde discurre la búsqueda de transformación en los sectores populares. La religiosidad popular es un espacio privilegiado para captar estos cauces. Desde el lenguaje del abordaje de las capacidades, podría afirmarse que ésta expresa por un lado la diversidad de sentidos e identidades de un pueblo, y a su vez su la "agencia” y búsquedas de transformación, sus anhelos y esperanzas. La religiosidad popular expresa la disconformidad de los "marginados" con estructuras que dejan de lado, que no integran, que no saben dialogar con lo que tienden a considerarse atrasado, premoderno, sin comprender que tienen semillas genuinamente vitales y transformadoras.

\section{UNIVERSO DE ESTUDIO Y FUENTE DE DATOS: SUS POSIBILIDADES Y LIMITACIONES}

El análisis que se efectúa en este artículo se basa en una muestra representativa de hogares de los siete barrios/"villas de emergencia" en los que el Programa Interdisciplinario de Organizaciones de la Sociedad Civil y Desarrollo Humano de la UCA viene trabajando desde el 2010. Los barrios son la villa del Bajo Flores (la 1-11-14), la villa de Barracas, Villa 19 de Lugano - barrio INTA -, Los Piletones, la villa 6 Cildañez, Villa 3 (Fátima más Calecita), y el barrio R. Carrillo junto con los Pinos. La población total en estos asentamientos es de 106.043 habitantes (CNPV 2010), lo que representa al $65 \%$ de la población total de "villas" de la ciudad. Son barrios localizados en el sur, y sur oeste de la ciudad.

En estos barrios en el 2010/2011 se aplicó un cuestionario a una muestra representativa de hogares compuestos por más de una persona. Se indagó sobre una variedad de dimensiones objetivas y subjetivas de sus condiciones de vida: características demográficas, migración internacional, vivienda y hábitat, conectividad y accesibilidad, seguridad, salud, alimentación, educación, actividades laborales y productivas, situación económica del hogar, integración social, vida familiar y religiosa. El cuestionario fue respondido por el/la jefe o cónyuge del hogar, quien para gran parte de las dimensiones informaba por el hogar en su conjunto o por cada uno de los componentes

Debates do NER, Porto Alegre, ANo I5, N. 25, P. 24I-270, JAn./Jun. 2014 
del mismo. Algunas de las preguntas, entre ellas las religiosas, corresponden solo a la situación del respondente. Como el cuestionario fue contestado en un $93,5 \%$ por mujeres, a los efectos de la presente caracterización se decidió eliminar el 6,5\% de respondentes varones y predicar solo de la condición religiosa de las mujeres de estos barrios. Se sacaron asimismo los pocos casos de respondentes menores de 18 años. El universo del presente estudio por lo tanto está conformado por mujeres mayores de 17 años, cónyuges o jefas de hogar, residentes en barrios precarios del sur/sur-oeste de la ciudad de Buenos Aires. El artículo se centra por tanto en la condición religiosa de mujeres.

Las preguntas específicamente vinculadas a lo religioso incluidas en el cuestionario fueron pocas pero relevan tres aspectos claves del involucramiento religioso: la creencia en Dios, la identidad y la práctica religiosa. ${ }^{7} \mathrm{Se}$ incluyeron dos preguntas vinculadas a autopercepción religiosa. ${ }^{8}$ Asimismo el cuestionario relevó la participación en organizaciones sociales, lo que permitió identificar la participación en instituciones religiosas. Finalmente se les preguntó a los/las respondentes su grado de confianza en instituciones y actores sociales entre los que figuraban algunos del ámbito religioso. Todas estas dimensiones son la base del análisis que se desarrolla a continuación sobre la situación religiosa de las mujeres en los asentamientos del sur de la ciudad de Buenos Aires. La caracterización es de tipo diacrónica. No existen datos similares previos con los cuales comparar. Esta carencia no permite caracterizar la dinámica del campo religioso ni hacer hipótesis de cambios en su estructura. El estudio se limita sólo a un análisis de la situación en el 2010/2011, o sea al momento de efectuarse el relevamiento. La similitud de algunos ítems de la situación religiosa recogidos por la EDSA del Barómetro

7 Las preguntas del cuestionarios fueron: a.Independientemente del hecho que vaya a la Iglesia, ¿Ud dirigía que es una persona religiosa, no religiosa o atea? b. ¿Cuál es la religión o credo al que pertenece?, c.Durante el último año, con qué frecuencia ha asistido al templo o iglesia?, d. Durante el último año ¿participó en alguna peregrinación, visita a santuario o procesión?

8 Las preguntas para esta dimensión fueron: a.Ud. considera que su grado de práctica religiosa es alto, medio o bajo; b.En los últimos años su práctica religiosa creció, disminuyó, o se mantuvo igual.

Debates do NER, Porto Alegre, ano I5, N. 25, P. 24I-270, JAn./Jun. 20 I4 
de la Deuda Social ${ }^{9}$ para el mismo período, hace posible la comparación de la situación de las mujeres en asentamientos con las del conjunto de la ciudad de Buenos Aires - CABA -, y del total del país. Comparación que se hará con cautela en los campos que lo permitan. Cabe mencionar que en el país los estudios que caracterizan el campo religioso a través de encuestas representativas son muy incipientes. El estudio reciente más relevante al respecto es la Primera encuesta sobre creencias y actitudes religiosas en Argentina realizada por el CEIL/CONICET recientemente publicado (Mallimaci, 2013) en el que tuve ocasión de participar en las etapas finales de análisis. En algunos aspectos donde sea factible me referiré a los resultados de dicho trabajo para comparar con el universo del presente estudio.

Interesa previo a adentrarnos en el análisis considerar algunas limitaciones que comporta estudiar el campo religioso a partir de datos secundarios recogidos en el marco de encuestas. La vinculación de las personas con lo religioso es un aspecto multidimensional, no observable de modo directo y por lo tanto difícil de aproximar. En el proceso de operacionalizarlo se corre el riesgo de perder la complejidad y variedad de matices que encierra esta vinculación. No existe ningún indicador que por sí solo de cuenta de lo que es identificarse con una religión y menos aún de lo que comporta ser una persona religiosa. Ambos aspectos son difíciles de observar y cualquier aproximación implica un recorte. 'Tener una religión' es una noción ambigua difícil de captar adecuadamente; 'ser una persona religiosa' es aún más difícil de definir u observar (Voas, 2007). Recoger los sentidos profundos que las personas encuentran en la religión, y cómo éstos infunden creencias, prácticas y acciones, requiere una baterías de preguntas que excede la fuente de datos que hemos utilizado en este caso; pero aún si se incluyeran más indicadores la captación sería siempre parcial (Suárez; López Fidanza, 2013). Con estas

9 El Programa realiza todos los años - a partir de 2004 - una encuesta nacional con indicadores de desarrollo humano e integración social (Encuesta de la Deuda Social Argentina) a hogares, poblaciones y niños residentes de áreas urbanas del país. Actualmente, en el marco del proyecto "La Argentina del Bicentenario 2010-2016", la encuesta releva 5700 hogares.

Debates do NER, Porto Alegre, ANo I5, N. 25, P. 24I-270, JAn./Jun. 2014 
limitaciones en mente, pasamos en las próximas secciones a caracterizar la situación religiosa de las mujeres de nuestro universo de estudio.

\section{CREENCIA EN DIOS, IDENTIDAD, PRÁCTICA Y PARTICIPACIÓN RELIGIOSA}

La creencia en un ser Supremo/Dios está sumamente extendida en la sociedad argentina. Solo una de cada diez personas afirma dudar o no creer en la existencia de Dios. ${ }^{10}$ Las mujeres tienden a ser levemente más creyentes que los varones (Suárez; Giorgi; Levita, 2013). La forma en que el relevamiento de la OSCDH se aproximó a esta dimensión no fue, como en el caso de la EDSA y la encuesta del CEIL-CONICET, con una pregunta directa sobre la creencia en Dios. A cada encuestado se le preguntó si independientemente del hecho de ir a la Iglesia, diría que es una persona religiosa, no religiosa o atea. El 85,4\% de las respondentes mujeres se identificaron con la primera categoría, un $11,3 \%$ con la segunda y un 3,3\% con la última. Con estos datos podemos afirmar que es ínfimo el porcentaje de mujeres de los asentamientos de la ciudad de Buenos Aires que se asumen como ateas. Sumando a las ateas el porcentaje de las que dijeron no ser personas religiosas (que seguramente - aunque no fue dado como una opción - se asumen como agnósticas), en las villas un 14,6\% de las mujeres es indiferente a lo religioso. No contando con datos que permitan comparar en el tiempo, toda lectura de este porcentaje es necesariamente sesgada. No sabemos si es una cifra que fue en aumento o si refleja una realidad que se ha mantenido por décadas ¿Es un porcentaje alto o bajo? Depende como quiera leerse; prefiero dejarlo a criterio del lector. Repitamos el valor de su complemento: 85,4\% que corresponde a quienes se identifican como personas religiosas. Se trata de un valor indudablemente alto. Para una gran mayoría de las mujeres de nuestro estudio la religión, independientemente de la forma que tome en su identidad y práctica religiosa, es parte de sus vidas.

${ }^{10}$ La EDSA 2011 y el relevamiento efectuado por el CEIL - Conicet arriban a porcentajes coincidentes en esta dimensión.

Debates do NER, Porto Alegre, ANo I5, N. 25, P. 24I-27O, JAN./Jun. 2014 
Una manera de darle forma a su "ser" religioso/a es adhiriendo a los marcos de una institución religiosa. Identidad, afiliación, autoafiliación y pertenencia son todas formas de nombrar las diversas formas de adherir a la variedad de denominaciones. No es este el lugar para dar una discusión de las diversas formas de nombrar este aspecto que en cada caso asume connotaciones específicas. Utilizaré identidad religiosa, la que debe entenderse más como verbo que como sustantivo, en el sentido que es construida y estructurada a la vez, dependiendo de los múltiples ámbitos de los que el individuo forma parte. ${ }^{11}$

La identidad religiosa mayoritaria de las mujeres de nuestro estudio es la católica $(70,7 \%)$, seguida del conjunto de denominaciones cristianas no católicas - evangélicas, pentecostales y adventistas - (13,1\%). Estos porcentajes evidencian la matriz cultural cristiana de nuestra sociedad.

La comparación con los datos de la EDSA revela en este punto algunas especificidades de las mujeres en espacios de alta vulnerabilidad social. El porcentaje de católicas de nuestro estudio es menor tanto al del conjunto de la población argentina, como al de la CABA. Lo contrario sucede con el porcentaje de evangélicas, que es sensiblemente superior, sobretodo al de la CABA - 1\% - (ver cuadro 1). Podría afirmarse que en la ciudad de Buenos Aires es en los asentamientos precarios donde se concentran las mujeres evangélicas/pentecostales. Este dato es consistente con diversos estudios que muestran que los evangélicos/pentecostales tienen una fuerte penetración entre los sectores más carenciados (Seman, 2010; Wynarczyk; Oro, 2012; Marzulli, 2011, entre varios otros). Los Testigos de Jehová y Mormones en cambio, tienen una presencia muy marginal en los asentamientos precarios (1\%); porcentaje inferior al que registran tanto en la CABA como en el total del país (ver cuadro 1).

11 Un desarrollo mayor de estos conceptos se encuentran en Suárez y López Fidanza 2013; publicación en la que destacamos que resulta de utilidad la distinción de niveles de análisis del concepto 'identidad' que postula Frigerio (2007): personal, social, colectiva (p. 101). La misma poco dice de las creencias de alguien, del compromiso con una institución religiosa o un modo de vida.

Debates do NER, Porto Alegre, ano I5, N. 25, P. 24I-270, Jan./Jun. 2014 
Cuadro 1 - Distribución de las mujeres según identidad religiosa y frecuencia de asistencia. Villas, CABA y total país

\begin{tabular}{|c|c|c|c|c|}
\hline Identidad religiosa & \multicolumn{2}{|c|}{ Villas } & $\begin{array}{c}\text { Ciudad de } \\
\text { Buenos Aires }\end{array}$ & TOTAL país \\
\hline Católica & \multicolumn{2}{|c|}{70.7} & 83.7 & 77.4 \\
\hline $\begin{array}{l}\text { Evangelico/Pentecostal/ } \\
\text { adventista }\end{array}$ & \multicolumn{2}{|c|}{13.1} & 1 & 9.3 \\
\hline Testigo de Jehová/Mormón & \multicolumn{2}{|c|}{1.0} & 3.3 & 2.6 \\
\hline Otra & \multicolumn{2}{|c|}{0.5} & & \\
\hline Sin identidad religiosa & \multicolumn{2}{|c|}{11.3} & 11.9 & 10.8 \\
\hline Atea & \multicolumn{2}{|c|}{3.3} & & \\
\hline Total & \multicolumn{2}{|c|}{$\begin{array}{l}100,0 \\
(597)\end{array}$} & $\begin{array}{c}100 \\
(393)\end{array}$ & 100,0 \\
\hline $\begin{array}{l}\text { Frecuencia de asistencia } \\
\text { al culto }\end{array}$ & $\%$ & $\%$ Ac & & \\
\hline Más de una vez por semana & 14.9 & 14.9 & 15.7 & \\
\hline Una vez por semana & 25.2 & 40.1 & & 20.6 \\
\hline Una vez por mes & 20.0 & 60.1 & & \\
\hline Cada varios meses & 25.0 & 85.1 & & \\
\hline Prácticamente nunca & 14.9 & 100.0 & 32.7 & 23.1 \\
\hline Total & $\begin{array}{l}100.0 \\
(516)\end{array}$ & & & \\
\hline
\end{tabular}

Notas: 1. La Encuesta OSC y la EDSA relevaron en forma diferente la creencia en Dios y la identidad religiosa. La mayor diferencia radica en que en la EDSA no se distingue entre sin religión y ateo. Las categorías construidas del cuadro respetan la comparabilidad.

2. En ambos relevamientos la pregunta sobre asistencia al culto no fue formulada a las personas sin religión o ateas.

Fuente de datos: Procesamientos propios en base a la Encuesta del Programa OSC 2010/2011, y a la Encuesta de la Deuda Social Argentina 2011 - UCA

12 Tanto en el relevamiento de la OSCDH, como en el de la EDSA la pregunta sobre frecuencia de asistencia al culto es igual: "Durante el ultimo año, dejando de lado casamientos, funerales, bautismos, etc, con qué frecuencia ha asistido al templo o Iglesia”. La pregunta así formulada se asegura que aquellas personas que fueron al templo por cuestiones estrictamente sociales queden fuera de las categorías correspondientes.

Debates do NER, Porto Alegre, ANo I5, N. 25, P. 24I-270, JAN./Jun. 2014 
La identidad religiosa, o sea la religión declarada, poco dice acerca de la variedad de formas de pertenecer, ni sobre el grado de adhesión y compromiso de las personas con lo religioso, y menos aun sobre la vivencia religiosa de las personas. Se requiere una batería de indicadores para aproximarnos a estos aspectos. La encuesta OSCDH incorporó dos indicadores que dicen algo acerca de la práctica religiosa de las personas: la frecuencia de asistencia al culto, y la participación en peregrinaciones o visitas a santuarios. En ambos casos son prácticas que tienen lugar en un espacio público con un componente comunitario: son ceremonias, cultos, caminatas que se realizan junto con varias personas. Las prácticas poco institucionalizadas (oraciones, promesas, "toma de gracia", etc...), que creemos que son ricas y variadas en estos barrios, quedan fuera. Comencemos por decir algo de la segunda: la participación durante el último año en alguna peregrinación o procesión. Estas conforman espacios donde la religiosidad popular se expresa y amplifica. Un tercio de las mujeres creyentes afirma haber participado. Son mujeres que se han sumado de esta forma a manifestaciones de fe que se caracterizan por realizarse en forma comunitaria en la vía pública. Tienen además la connotación de implicar un camino, un recorrido, que bien puede tener valor simbólico como recurso para un camino y "purificación" interior.

Me detendré más en la otra práctica religiosa relevada por la OSCDH, la frecuencia de la asistencia al culto, ya que es el aspecto más usualmente tomado en estudios agregados para dar cuenta del grado de compromiso de las personas con su fe y con la institución religiosa de pertenencia. Que sea el más usualmente utilizado, tal vez no signifique más que eso. El grado de correspondencia con lo que se supone que mide puede legítimamente cuestionarse. Conscientes de las limitaciones del indicador, veamos qué valores alcanza en nuestro universo de estudio. ${ }^{13}$ Cuatro de cada diez mujeres "creyentes" residentes en villas de la CABA afirman asistir al menos una vez a

${ }^{13}$ Cabe destacar que las mujeres tienden a asistir al culto más que los varones. El relevamiento efectuado por el CEIL - Conicet muestra que en argentina solo un quinto de las mujeres nunca participa de las ceremonias de su culto, mientras que un tercio de los varones nunca lo hace. Asimismo asisten al menos una vez a la semana a su culto casi un cuarto de la población argentina, proporción que aumenta a casi un tercio en la mujeres y disminuye a un quinto entre los varones (Suárez; Giorgi; Levita, 2013, p. 146).

Debates do NER, Porto Alegre, ano I5, N. 25, P. 24I-270, Jan./Jun. 2014 
la semana a su culto; un quinto lo hace al menos una vez por mes; un cuarto lo hace cada varios meses; y casi un 15\% declara no asistir nunca (ver cuadro 1). Para darle contexto a estos valores analicemos cómo se comparan con los del total de mujeres de CABA y del país. La EDSA muestra que para CABA y total país el $15,7 \%$ y $20,6 \%$ respectivamente asiste al menos una vez por semana, mientras que el $32,7 \%$ y $23,1 \%$ respectivamente nunca lo hace (ver cuadro 1). Se deduce fácilmente que las mujeres en asentamientos son más "practicantes" que sus pares fuera de la villa en la CABA y que las del total país; y un grupo importante - $40 \%$ - son muy practicantes. ¿Cómo darle una interpretación consistente a esta elevada cifra de práctica religiosa? Traducido a cifras absolutas, aproximadamente 10.000 mujeres mayores de 17 años asisten semanalmente a su culto, cifra que seguramente alcanzaría los 20.000 considerando las niñas y todos los varones; y que sube aun más si prorrateáramos a los que dicen que asisten al menos una vez por mes (20\%). Difícilmente ninguno de los sacerdotes y pastores de los siete asentamientos acordaría con estas cifras. Las capillas, las parroquias y los templos estarían abarrotados de gente durante los escasos servicios de culto en cada una de ellas los fines de semana. Tampoco estamos en condiciones de dudar de la veracidad de lo declarado por las personas ni del relevamiento efectuado. ${ }^{14}$ ¿Por qué? La gente tiende a exagerar mucho su asistencia a servicios religiosos. Es un tema que ha sido ya estudiando para diversos contextos; es de hecho una constatación a la que arriba D. Voas (2007) sobre la base de diversos trabajos empíricos que muestran que efectivamente hay una fuerte disparidad entre lo que la gente declara en las encuestas sobre su asistencia y el recuento en los lugares de culto de las personas que efectivamente asistieron. La explicación que da Voas, 2007 a esta disparidad es que la gente responde en función de un sentimiento subjetivo de regularidad, que traduce en lo que supone debería ser su participación, pero que en realidad no es más que un deseo o una conciencia de lo esperado. Así, lo que podemos inferir con estos porcentajes es interesante pero complicado de analizar. Por un lado

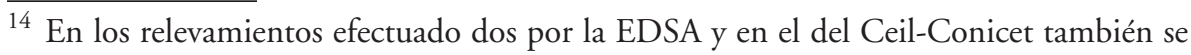
presenta la misma situación: el porcentaje de personas que afirman asistir al menos semanalmente a su culto es llamativamente alto.

Debates do NER, Porto Alegre, ANo I5, N. 25, P. 24I-270, JAN./Jun. 20 I4 
sugiere que la asistencia al culto tiene un fuerte valor simbólico en nuestra sociedad, y que es particularmente alto en los sectores más marginados. Tal vez lo que más esté indicando el dato es que más allá del acto concreto de asistir o no a un culto, o de conocer o adherir a todos los preceptos de la institución religiosa, hay una conexión, una afinidad con el universo simbólico asociado a la institución; tal vez exprese asimismo la valoración de adherir a una forma de expresar comunitariamente una vivencia y pertenencia; o sea una voluntad de "caminar" acompañado.

Desde los argumentos de los párrafos de arriba, cobra también sentido otro indicador utilizado en el relevamiento de la OSCDH, en este caso más directamente subjetivo, traducido en la pregunta ¿Ud. considera que su práctica religiosa es: Alta, media o baja? Tres cuartos de las mujeres creyentes afirman que la misma es alta o media (ver cuadro 2). El porcentaje es muy alto; es asimismo complejo de analizar; ¿qué entiende cada mujer por práctica religiosa? ¿Con qué aspectos y acciones de su vida la asocia? ¿La entiende solo como acciones concretas, o piensa también en vivencias y sentidos? Imposible saber con este tipo de encuestas. Lo que sí dice es que para un grupo relevante de mujeres lo religioso tiene importancia en sus vidas. Una importancia que tiende a mantenerse estable en el tiempo; o sea a hacer parte natural de sus vidas cotidianas. Creemos que el hecho que dos tercios de las mujeres haya afirmado que su práctica religiosa en los últimos años se mantuvo igual es indicativo de este argumento (ver cuadro 2 ). A su vez son más las que indican que ésta creció $(23,5 \%)$, que las que aseveran que disminuyó $(8,9 \%)$.

Cuadro 2 - Distribución porcentual de las mujeres en villas según autopercepción de la práctica religiosa

\begin{tabular}{|l|c|c|}
\hline Ud. Considera que su práctica religiosa es... & $\%$ & $\%$ acumulado \\
\hline Alto & 21.4 & 21.4 \\
\hline Medio & 53.5 & 74.9 \\
\hline Bajo & 25.1 & 100.0 \\
\hline \multirow{2}{*}{ Total } & 100.0 & \\
& $(518)$ & \\
\hline
\end{tabular}

Debates do NER, Porto Alegre, Ano I5, N. 25, P. 24I-270, JAn./Jun. 20 I4 


\begin{tabular}{|l|c|c|}
\hline En los últimos años, su práctica religiosa... & & \\
\hline Creció & 23.5 & 23.5 \\
\hline Disminuyó & 8.9 & 32.4 \\
\hline Se mantuvo igual & 67.6 & 100.0 \\
\hline Total & $\begin{array}{l}100.0 \\
(519)\end{array}$ \\
\hline
\end{tabular}

Nota: contestan sólo quienes se identifican con alguna religión.

Fuente: Procesamientos propios en base a la Encuesta del Programa OSC 2010/2011

Hemos analizado hasta acá una aproximación a la identidad y a la práctica religiosa de las mujeres de nuestro universo de estudio. ¿Cómo se relacionan entre sí ambos aspectos? Debido a la cantidad de casos de la muestra, en aras de asegurar la significación de los cruces entre ambas variables, se agruparon las identidades religiosas en dos: católica, y religiosa no católica. En esta última categoría se ubican las mujeres evangélicas/pentecostales y adventistas, y las Testigos de Jehová y Mormonas. Cabe recordar que el grueso de la segunda categoría lo componen las evangélicas/pentecostales. En una tercera categoría se agruparon a las ateas y las que se declaran sin religión.

Las mujeres no católicas (o sea básicamente las evangélicas/pentecostales) tienen una frecuencia de asistencia al culto mayor que sus pares católicas. Perciben asimismo que su práctica religiosa es alta en mayor medida que las católicas, y afirman que su vida religiosa creció en los últimos años más que las católicas (ver cuadro 3). Estos datos son consistentes con lo que diversos estudios, sobretodo de índole cualitativo, vienen mostrando sobre el dinamismo del mundo evangélico en Argentina, tendientes a generar mayor compromiso entre sus adherentes particularmente en los sectores más carenciados (Seman, 2010; Wynarczyk, 2012, entre otros). La adhesión a la propuesta evangélica se traduce en prácticas, que en muchos casos, incorporan sin mayores conflictos aquellas más vinculadas a la esfera católica. Según datos recientes un quinto de los evangélicos tienen creencias (virgen, santos) y prácticas (confesarse y comulgar, peregrinaciones a santuarios) que ponen de manifiesto que junto a su adscripción evangélica, presentan una 
religiosidad íntimamente vinculada al catolicismo (Algranti et al., 2013). Los datos de la OSCDH no permiten ahondar en este tema, por lo que lo expresado en la frase de arriba podría observarse con mayor o menor medida en los barrios estudiados. No lo sabemos. Nuestra hipótesis en este tema es que en los espacios que hemos estudiado, las dos identidades cristianas mayoritarias: católica y evangélica, son adscripciones móviles, sobretodo en el segundo caso. Desde la perspectiva de las personas que adscriben es compatible compartir creencias y prácticas de ambos espacios religiosos. La fluidez y la movilidad están marcadas, entre otros aspectos, por la "oferta" que encuentran en cada espacio y la posibilidad que les brindan de expresar su fe y sentirse "agentes", en el sentido que hemos desarrollado en el marco conceptual del trabajo. Cabe destacar finalmente que tratándose de espacios marginales, la oferta en el propio territorio es vital. Que las capillas estén cerca del lugar donde residen va marcando pautas de adhesión. Creemos que en buena parte, para muchos, la cercanía a los lugares de culto tiene una influencia muy importante en la conformación de adhesiones y prácticas. La participación en instituciones religiosas, muestra la relevancia del argumento que se está haciendo. Casi 9 de cada 10 mujeres afirman que la parroquia o templo en la que participan está dentro de sus propios barrios.

Cabe aquí dejar planteada un interrogante para ser ahondado desde perspectivas cualitativas. Siguiendo la argumentación de Rita Segato, entre otros, respecto a que la identidad no es generada porque se comparta un territorio común sino que es la identidad la que genera, instaura, el territorio (Segato, 2008, p. 46); ¿ cómo el tipo de fluidez y de movilidad religiosa en los espacios de marginalidad urbana van perfilando una identidad religiosa de fronteras borrosas en espacios que en la vida cotidiana de sus habitantes están atravesados por el aislamiento y la escasa integración a la trama urbana? Fluidez y fronteras borrosas por un lado, y aislamiento y poca integración por otro, son coordenadas por las que el territorio en el que habitan los sectores urbanos más marginados va adquiriendo su propia identidad.

Para concluir este apartado, queda decir unas palabras sobre la participación en actividades que se desarrollan en instituciones religiosas. En el cuestionario de la OSCDH se les dio a los respondentes un listado de 13

Debates do NER, Porto Alegre, ANo I5, N. 25, P. 24I-270, JAn./Jun. 2014 
instituciones, grupos o asociaciones; se les solicitó que indicaran para cada una: a.si regularmente participan o no; b.el nombre de la institución; c.si se encuentra en el barrio o no, y d.en qué consiste, según sus propias palabras, su participación. Se dejó un ítem abierto para que indicaran alguna otra institución no incluida en el listado. Los resultados son los siguientes: de los 13 tipos de instituciones, las que concentra los mayores porcentajes son las instituciones religiosas (parroquia, iglesia o templo, según la formulación específica de la pregunta). Un 27,1\% de las mujeres encuestadas lo hace regularmente (ver cuadro 4). Su participación es muy variada; una lectura rápida a sus respuestas abiertas en este ítem, revela que lo hacen como voluntarias, en Cáritas, en los scouts, en diversos cursos o charlas, en la catequesis, etc... El análisis de la participación, más que decir algo de la subjetividad y religiosidad de las mujeres - aspectos a los que no se refiere -, permite decir unas palabras acerca las instituciones religiosas en estos barrios. Son las instituciones que logran nuclear la mayor participación. Junto con los comedores - que nuclean un 20\% de participación- son las únicas que tienen una participación importante. Las 11 restantes nuclean porcentajes que oscilan entre 6,7\% y $0,5 \%$ (ver cuadro 4). El dato de la participación en instituciones religiosas del barrio cobra mayor relieve al compararlo con otros contextos en los que el valores más bajo. ${ }^{15}$ Que en cambio la participación en general y en las parroquias en particular sea más alta en espacios de marginalidad, creemos que es un dato relevante que tal vez sea indicativo del rol de la parroquia en tanto espacio que articula participación, contención y socialización. Nuestras aproximaciones personales - "etnográficas"- a estos espacios sugieren que las parroquias, templos y demás lugares vinculados al culto, adquieren para los pobladores de los asentamientos connotaciones peculiares, que van más allá de ser espacios para la práctica religiosa; son espacios donde, por las situaciones de vida de los habitantes de asentamientos, las personas, a través de las actividades propuestas, "suman" en las varias dimensiones que hacen a las posibilidades de ir ganando "agencia" y autonomía.

15 La reciente publicación de Cao, Cecconi y Balian (2011) muestra que la participación periódica es del $18 \%$, siendo la participación en instituciones religiosas la que alcanza el mayor porcentaje.

Debates do NER, Porto Alegre, ano I5, N. 25, P. 24I-270, JAn./Jun. 20 I4 
Cuadro 3 - Frecuencia y autopercepción de la práctica religiosa según identidad religiosa

\begin{tabular}{|c|c|c|}
\hline \multirow{2}{*}{$\begin{array}{l}\text { Frecuencia } \\
\text { de asistencia al culto }\end{array}$} & \multicolumn{2}{|c|}{ Identidad religiosa } \\
\hline & Catolica & Religiosa no católica \\
\hline $\begin{array}{l}\text { Al menos una vez por } \\
\text { semana }\end{array}$ & 35.5 & 62.1 \\
\hline Una vez por mes & 20.4 & 14.9 \\
\hline Cada varios meses & 27.0 & 17.2 \\
\hline Prácticamente nunca & 17.1 & 5.7 \\
\hline Total & $\begin{array}{l}100.0 \\
(422)\end{array}$ & $\begin{array}{c}100.0 \\
(87)\end{array}$ \\
\hline \multicolumn{3}{|c|}{ Ud. considera que su práctica religiosa es... } \\
\hline Alto & 18.0 & 37.6 \\
\hline Medio & 53.6 & 56.5 \\
\hline Bajo & 28.4 & 5.9 \\
\hline Total & $\begin{array}{l}100.0 \\
(422)\end{array}$ & $\begin{array}{c}100.0 \\
(85)\end{array}$ \\
\hline \multicolumn{3}{|c|}{ En los últimos años, su práctica religiosa... } \\
\hline Creció & 19.4 & 41.9 \\
\hline Disminuyó & 9.0 & 7.0 \\
\hline Se mantuvo igual & 71.6 & 51.2 \\
\hline Total & $\begin{array}{l}100.0 \\
(422)\end{array}$ & $\begin{array}{c}100.0 \\
(86)\end{array}$ \\
\hline
\end{tabular}

Fuente: Procesamientos propios en base a la Encuesta del Programa OSC 2010/2011.

Debates do NER, Porto Alegre, ano I5, N. 25, P. 24I-270, JAn./Jun. 2014 
Cuadro 4 - Participación en instituciones, grupos o asociaciones (\%)

\begin{tabular}{|l|c|c|c|c|}
\hline \multirow{2}{*}{ Institución, grupo o asociación } & \multicolumn{3}{|c|}{ Identidad religiosa } \\
\cline { 2 - 5 } & Católica & $\begin{array}{c}\text { Religiosa } \\
\text { no católica }\end{array}$ & $\begin{array}{c}\text { Sin } \\
\text { religion } \\
\text { o atea }\end{array}$ & Total \\
\hline Parroquia/Iglesia/Templo & 32.0 & 27.6 & 3.4 & 27.1 \\
\hline Comedor & 22.0 & 26.4 & 8.0 & 20.6 \\
\hline Cooperadora Escolar & 7.6 & 5.7 & 3.4 & 6.7 \\
\hline Asambleas Barriales & 3.1 & 4.6 & 0.0 & 2.8 \\
\hline Centro Cultural o Club & 2.4 & 3.4 & 1.1 & 2.3 \\
\hline Grupos de Ayuda & 2.4 & 3.4 & 1.1 & 2.3 \\
\hline Junta Vecinal & 2.1 & 1.1 & 0.0 & 1.7 \\
\hline Cooperativa de Trabajo & 1.4 & 2.3 & 2.3 & 1.7 \\
\hline Asociación de la Colectividad & 1.2 & 2.3 & 2.3 & 1.5 \\
\hline Movimiento Social & 1.4 & 2.3 & 1.1 & 1.5 \\
\hline Equipo de fútbol o grupo artístico & 1.7 & 1.1 & 1.1 & 1.5 \\
\hline Partido Político & 0.5 & 1.1 & 0.0 & 0.5 \\
\hline Sindicato/Gremio & 0.2 & 0.0 & 0.0 & 0.2 \\
\hline
\end{tabular}

Fuente: Procesamientos propios en base a la Encuesta del Programa OSC 2010/2011.

\section{IDENTIDAD Y PRÁCTICA RELIGIOSA SEGÚN NIVEL DE INSTRUCCIÓN, GRUPOS DE EDAD, SITUACIÓN CONYUGAL Y CONDICIÓN MIGRATORIA}

En el apartado de arriba caracterizamos la situación religiosa de las mujeres de los siete asentamientos precarios del sur de CABA. Lo hicimos considerando la identidad, la práctica y participación religiosa de las mujeres 
en su conjunto, comparando en algunos casos con la situación religiosa de mujeres de toda la CABA y del total del país. En este apartado dejamos de lado la comparación con otros contextos, y nos preguntamos qué especificidades encontramos entre las mujeres de estos barrios. Nos preguntamos más concretamente si la situación religiosa de las mujeres varía o introduce especificidades en función de aspectos sociodemográficos básicos: nivel de instrucción, grupos de edad, situación conyugal y condición migratoria. El análisis que sigue destacará solo aquellas situaciones donde observamos alguna influencia de los aspectos en cuestión, y para no extendernos, no presentamos las tablas.

Analizamos primero la influencia del nivel de instrucción. Las mujeres en estos barrios presentan niveles de instrucción muy bajos. Un grupo relevante, $28,5 \%$ no completó la primaria; casi la mitad tiene como máximo nivel educativo el secundario incompleto. $\mathrm{O}$ sea tres cuartos de las mujeres no concluyó el secundario. No es el espacio aquí para profundizar en estos datos, nos preguntamos simplemente si los diferentes niveles de instrucción alcanzados (hasta primaria incompleta, primaria completa/secundario incompleto, y secundario incompleto y más), influencian de alguna manera en la identidad y práctica religiosa. Lo hacemos asumiendo que al estar el nivel educativo de las personas en la sociedad argentina asociado a la estratificación social, posiblemente en los barrios precarios de la CABA los sectores sociales con niveles educativos más bajos se correspondan con aquellos de niveles socioeconómicos bajos dentro de estos barrios; $\mathrm{y}$ a su vez los niveles educativos más altos tiendan a corresponderse con sectores un poco más altos en la estratificación socioeconómica de estos espacios.

La influencia del nivel de instrucción en la identidad religiosa es muy baja, y prácticamente insignificante. Cabe solo destacar una leve tendencia que indica que las católicas presentan mayores niveles de instrucción que el resto, y que las ateas o sin religión niveles un poco más bajos. Una influencia también muy leve se observa en la práctica religiosa. Las mujeres con los niveles de instrucción más bajos tienden más que el resto a tener una práctica frecuente cuando ésta se mide con la asistencia al culto y por la autopercepción respecto al grado de su práctica. En cambio esta influencia desaparece con

Debates do NER, Porto Alegre, ANo I5, N. 25, P. 24I-270, JAn./Jun. 2014 
la participación en peregrinaciones o procesiones; un tercio de las mujeres participan en las mismas con independencia de su nivel educativo.

Tampoco la edad tiene una clara influencia ni en la identidad ni en la práctica religiosa. Entre las mujeres evangélicas la influencia pareciera ser nula. Entre las católica y entre las sin religión se observa una leve influencia: las católicas tienden un poco más a concentrarse en los grupos de edad más altos, y las sin religión entre las más jóvenes. En la práctica religiosa se observa que el grupo de edad ejerce una influencia un poco mayor: las mujeres más grandes tienden a tener una asistencia al culto y a peregrinaciones más frecuente que sus pares más jóvenes. Manifiestan asimismo en mayor medida que las jóvenes que su práctica religiosa ha tendido a crecer en los últimos años. Las jóvenes en cambio tienden a manifestar que se mantuvo igual. Los datos son consistentes con lo observado en diversos estudios. Efectivamente a medida que se avanza en la adultez de la vida y en la tercera edad, la religión cobra mayor fuerza (ver Suárez, 2013, entre otros). Esta constatación puede ser indicativa de dos situaciones: que las más adultas expresan socializaciones primarias en las cuales la religión tenía mayor fuerza que en la actualidad; o que al avanzar en edad se retoma con mayor fuerza a lo religioso en tanto contexto simbólico. Posiblemente ambas hipótesis sean ciertas para las mujeres en los barrios del estudio.

Las mujeres respondentes a la encuesta de la OSCDH en sus hogares son jefas o cónyuges. Analizamos si se observaba alguna diferencia entre ambos grupos en sus identidades o prácticas religiosas. No se observa ninguna. Tampoco el estado civil pareciera ejercer influencia alguna. Estar casada por civil, unida de hecho, separada o divorciada, viuda o soltera no se asocia en forma alguna a la situación religiosa. Estas constataciones que surgen del análisis cuantitativo plantean numerosas preguntas para ser abordadas desde aproximaciones cualitativas.

Analizamos finalmente la influencia de la condición migratoria. Aquí sí se observa algún nivel de influencia. Las mujeres provenientes del interior del país registran comportamientos en su identidad religiosa y en su práctica, similares a los del total de mujeres. Las diferencias se observan entre las 
nativas del Area metropolitana de Buenos Aires - AMBA - y las extranjeras. Las mujeres provenientes de otros países - que son principalmente países limítrofes - tienden a ser católicas en mayor medida que las nacidas en el AMBA o el resto del país. Asimismo su práctica religiosas tanto a través de la participación en ceremonias de sus cultos, como en peregrinaciones, tiende a ser levemente más alta entre las mujeres provenientes del extranjero. En el AMBA, a su vez, se registran mayores porcentajes que afirman no asistir nunca ni al culto ni a peregrinaciones. ¿Cómo interpretar estas leves tendencias? Un argumento posible, entre otros que deberían indagarse, es que al arribar al país las mujeres encuentran en la identidad religiosa y sobre todo en las prácticas una forma de mantener y recrear la cultura de sus lugares de origen. Los siete barrios del estudio se caracterizan de hecho por aglutinar a comunidades de extranjeros (sobretodo bolivianos, paraguayos, peruanos) en torno a celebraciones variadas en las que se expresan la riqueza de sus culturas. Lo religioso es un componente relevante en estas celebraciones, en las que además se estrechan vínculos entre los miembros de las comunidades.

\section{CONFIANZA EN LAS INSTITUCIONES}

La encuesta OSCDH incluyó ítems para medir el grado de confianza en actores sociales y en instituciones. Se les presentó un listado de 10 actores y de 14 instituciones, y para cada uno de ellos se le solicitó al respondente que marcara si su confianza era mucho, algo o nada. El gráfico 1 presenta los resultados. Los porcentajes consignados corresponden a la suma de los porcentajes de mucho y algo de confianza. De las instituciones, la Iglesia católica está en segundo lugar por debajo de la escuela pública que es la que mayor porcentaje obtuvo. Un $76,7 \%$ de las mujeres confían en la Iglesia católica. El porcentaje tiende a subir levemente entre las mujeres católicas y a bajar entre las evangélicas. Cabe destacar que entre las mujeres sin religión el porcentaje de confianza es bastante alto $(64,8 \%)$; este dato es interesante por cuanto es indicativo que la confianza en la Iglesia católica se construye

Debates do NER, Porto Alegre, ANo I5, N. 25, P. 24I-270, JAn./Jun. 20 I4 
independientemente de la adhesión personal a sus postulados. El dato es consistente con lo reportado por otros relevamientos, en los que la Iglesia católica también aparece en los primeros lugares del ranking. En los barrios marginados hay un entramado organizativo denso; las organizaciones son de diversa índole y realizan diversas acciones que buscan beneficiar a sus habitantes (Mitchell, 2012). El mayor nivel de confianza en la Iglesia católica respecto a otras organizaciones puede leerse como un apoyo al tipo de actividad que las parroquias y capillas despliegan en estos barrios.

El alto nivel de confianza en la iglesia católica (ver gráfico 1) se corresponde con un igualmente alto nivel de confianza en los sacerdotes, quienes ocupan el tercer lugar en el ranking por debajo de los médicos y maestros. El 71,9\% de las mujeres expresan su confianza en ellos. Podría leerse el valor de este porcentaje como una legitimización al trabajo que realizan los "curas villeros" en estos barrios. Su trabajo está sostenido y priorizado desde la Arquidiócesis de Buenos Aires. ${ }^{16}$

Cabe leer el alto nivel de confianza tanto en la iglesia católica como en los agentes más comprometidos dentro de ella en vinculación con el igualmente alto nivel de participación en la iglesia. En el apartado 3 destacamos que los lugares de culto (parroquias/capillas/templos), son los espacios en los que los habitantes de estos barrios más participan, y que lo hacen desarrollando una variedad de actividades. Queda también aquí simplemente enunciada la correspondencia, y nuevamente la promesa de ahondar en el tema desde perspectivas cualitativas que permitan comprender las connotaciones que toma esta participación para la vida de las personas y de las comunidades.

\footnotetext{
${ }^{16}$ Cabe mencionar que los curas cubren solo una parte del espectro de actores religiosos católicos presentes en estos espacios; en varios de los barrios viven y trabajan religiosas y laicos/as comprometidos. Lamentablemente no se los incluyó en el cuestionario como actores. Tampoco se incluyeron pastores o agentes religiosos evangélicos. Estas omisiones dejan solo a los curas como actores religiosos de estos espacios. Se pierden por tanto aspectos relevantes del análisis, que pueden llevar a simplificaciones en las interpretaciones.
}

Debates do NER, Porto Alegre, ANo I5, N. 25, P. 24I-27O, JAN./Jun. 2014 
Gráfico 1 - Porcentaje de Confianza (mucho y algo) en actores e instituciones según identidad religiosa

Ordenadas de mayor a menor confianza sobre el porcentaje del total Instituciones

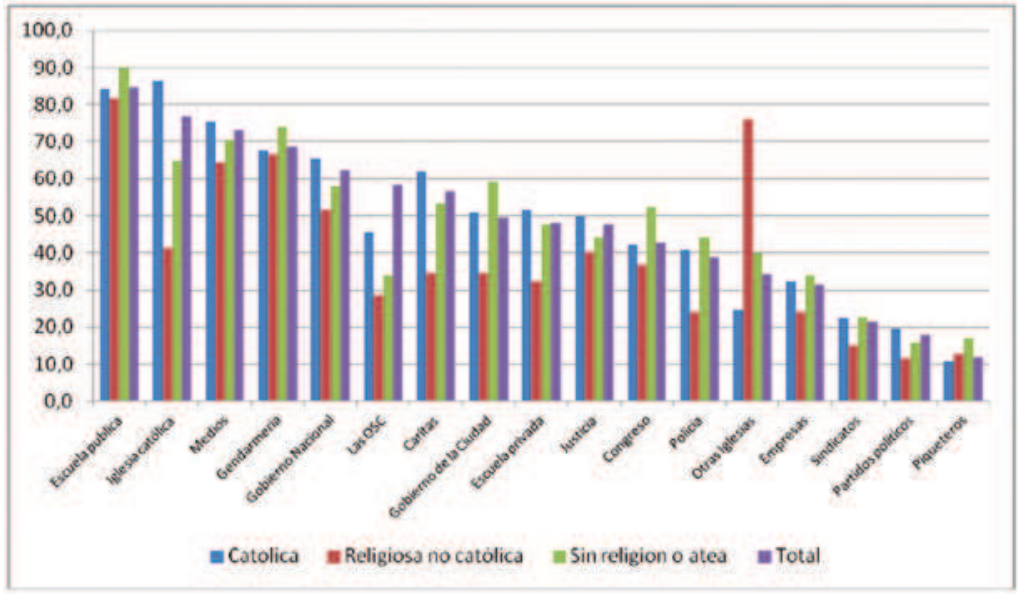

Actores

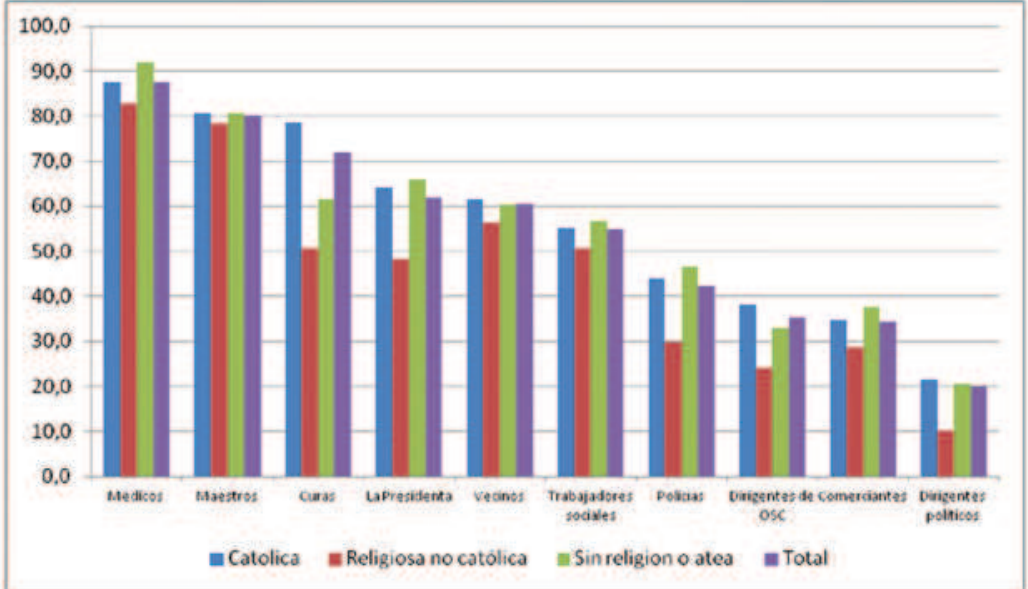

Fuente: Procesamientos propios en base a la Encuesta del Programa OSC 2010/2011.

Debates do NER, Porto Alegre, ANo I5, N. 25, P. 24I-270, JAN./JUn. 2014 


\section{REFLEXIONES FINALES}

Resumiendo los datos principales del análisis se puede afirmar que para una gran mayoría de las mujeres en asentamientos precarios de Buenos Aires la religión, independientemente de la forma que tome en su identidad y práctica religiosa, es parte de sus vidas. La identidad religiosa mayoritaria es la católica aunque el porcentaje es menor al del conjunto de la Argentina; seguida del conjunto de denominaciones cristianas no católicas - evangélicas, pentecostales y adventistas; porcentaje que es más alto tanto al de la CABA como al resto del país, permitiendo afirmar que las evangélicas tienden a concentrarse en sectores de mayor marginalidad urbana. Asumiendo que la fe se expresa en parte a través de prácticas institucionalizadas, la adhesión alcanza valores medios tanto en aquellas con menor grado de institucionalización - peregrinaciones, procesiones, visitas a santuarios; como en las de mayor grado, como es la asistencia al culto. Los datos sugieren que estas mujeres adhieren a las prácticas propuestas por las instituciones con "libertad” y que su vida religiosa tiene también otros causes de expresión, lo que se manifiesta en el alto porcentaje que manifiesta percibirse como con una práctica religiosa alta o media. La encuesta efectuada no permite analizar a qué tipo de prácticas refieren, ni en qué basan esta percepción. Todos los indicadores utilizados para medir la práctica religiosa son más altos entre las evangélicas, lo que sugiere que entre las evangélicas el "compromiso" religioso es mayor.

En la situación religiosa de las mujeres de estos barrios marginales, tienen muy poca incidencia dimensiones sociodemográficas como el nivel de instrucción, la edad y el estado civil. Solo la situación migratoria tiene cierta incidencia observándose mayores niveles de práctica religiosa entre las mujeres migrantes. Finalmente del relevamiento vinculado a participación y confianza en instituciones y en actores sociales, se destaca la relevancia que tienen los "espacios" y actores religiosos en estas áreas urbanas marginales.

Como reflexión final del trabajo quisiera articular el análisis cuantitativo efectuado con el marco conceptual propuesto y con algunas proposiciones que surgen de investigar, pensar y "sentir" la presencia religiosa en espacios

Debates do NER, Porto Alegre, ANo I5, N. 25, P. 24I-270, JAN./JUn. 2014 
de marginalidad urbana. Retomo el argumento del primer párrafo del presente trabajo: la religiosidad en estos espacios se palpa, se siente. Es una presencia que se manifiesta de diversas maneras - imposibles de captar solo con un abordaje cuantitativo - y que en parte remite a una matriz cultural donde lo religioso de anclaje cristiano es una dimensión constitutiva. Matriz cristiana que fue adquiriendo variedad de formas, enriquecida por tradiciones, costumbres, culturas que convergen en espacios urbanos signados por una cierta homogeneidad en términos socioeconómicos. Miradas académicas que analizan la religión desde el prisma de la secularización o desde la institucionalidad religiosa, corren el peligro de no captar procesos de subjetivación, de "agencia" y de esperanzas de transformación social vinculados a "lo religioso" en estos espacios. El "flujo" religioso en alguna medida converge con lo institucional; de ahí tal vez el alto grado de confianza y sobre todo de participación en espacios religiosos: parroquias, templos; y otros tantos no captados directamente por las encuestas: como casas de la mujer, de rehabilitación, etc. vinculadas a comunidades religiosas. Son espacios cuyo efectos en términos de reconocimiento personal y social, de "agencia" y capacidad transformadora no han sido aun indagadas en profundidad. Es un flujo, el religioso, que a su vez converge en parte y tiende a mantener vigente dimensiones de la cultura popular como la cosmológica, la holística y la relacional (Seman, 2001), que le habilita vías de expresión, y a su vez de renovación de lo religioso en tanto sistema instituido. Captar esta convergencia desde las ciencias sociales no es fácil. El desafío mayor es construir adecuados marcos conceptuales. Queda aún mucho camino por recorrer en esa dirección.

\section{REFERENCIAS}

ALBADO, Omar César. La crítica de la cultura como deconstrucción del concepto de Dios. El aporte de la escuela argentina de teología al debate sobre modernidad y secularización. In: TOURIS, Claudia; CONTARDO, María Florencia. (Editoras) Actas de las Terceras Jornadas de Religión y Sociedad en la Argentina Contemporánea y paises del Cono Sur (III RELIGAR-SUR)/

Debates do NER, Porto Alegre, ANo I5, N. 25, P. 24I-270, JAn./Jun. 2014 
$V$ Jornadas de Religión y Sociedad en Argentina. Buenos Aires: RELIG-AR Ediciones, 2013.

ALGRANTI, Joaquín et al. Evangélicos en la Argentina. Perfiles y formas de pertenencia religiosa. In: MALLIMACI, Fortunato. Atlas de las creencias religiosas en la Argentina. Buenos Aires: Biblos, 2013.

AMEIGEIRAS, Aldo Religiosidad popular. Creencias religiosas populares en la sociedad argentina. Buenos Aires: Biblioteca Nacional-UNGS, 2008.

BRADLEY, Tamsin Physical Religious Spaces in the Lives of Rajasthani Village Women: Ethnographic Study and Practice of Religion in Development. In: Journal of Human Development and Capabilites, v. 10, marzo 2009, p. 43-62.

CAO, Cristina; CECCONI, Elida; BALIAN, Beatriz. La sociedad civil argentina en el Bicentenario. Índice CIVICUS de la Sociedad Civil (20082010). Buenos Aires: Gadis, 2011.

DENEULIN, Severine; BANO, Masooda. Religion in Development: Rewriting the Secular Script. London/New York: Zed Books, 2009.

DENEULIN, Severine. An Introduction to the Human Development and Capability Approach. Freedom and Agency. (Edit.) London: Earthscan, 2009b.

FRIGERIO, Alejandro. Repensando el monopolio religioso del catolicismo en la Argentina. In: Ciencias sociales y religión en América Latina: Perspectivas en debate, editado por CAROZZI, M. J.; CERIANI, C. Buenos Aires: Biblos/ACSRM, 2007. p. 85-116.

LEAL, Claudia. La noción de justicia en Martha Nussbaum. In: Moralia 35, 2012.

LOPEZ FIDANZA, Juan Martin; GALERA, Cecilia. Religiosidad popular en el siglo XXI: Transformaciones de la devoción a San la Muerte en Buenos Aires. Estudios Cotidianos n.1. v. 1, p. 84-99, 2012.

MARTINEZ, Ana Teresa. En torno a la noción de campo religioso. Categorías para estudiar religión y política en América Latina. In: BELIVEAU, Verónica 
Gimenez; GIUMBELLI, Emerson. Religión, Cultura y politica en las sociedades del siglo XXI. Buenos Aires: Biblos, 2013.

MARZULLI, Pablo. "La Iglesia Bautista en el área metropolitana. Evolución y percepción de sus líderes". Tesis de Maestría en Sociología. UCA. Buenos Aires, 2011.

MITCHELL, Ann. Las organizaciones de la sociedad civil en las villas de Bajo Flores y de Barracas. In: LÉPORE, Eduardo. et al. Capacidades de desarrollo y sociedad civil en las villas de la ciudad. Buenos Aires: Educa, 2012.

NUSSBAUM, Martha. Las mujeres y el desarrollo humano. Herder: Barcelona, 2002.

SEGATO, Rita Laura. La faccionalización de la república y el paisaje religioso como índice de una nueva territorialidad. In: ALONSO, Aurelio. (Compilador) América Latina y el Caribe. Territorios religiosos y desafíos para el diálogo. CLACSO, Consejo Latinoamericano de Ciencias Sociales. Buenos Aires, 2008.

SEMAN, Pablo. Diferencia y transversalidad en la religiosidad de los sectores populares: mirando con telescopio luego de haber usado el microscopio. Apuntes de investigación del CECYP n.18, p. 71-107, 2010.

- Cosmológica, holística y relacional: una corriente de la religiosidad popular contemporánea. Ciencias Sociales y Religión/Ciências Sociais e Religião. n. 74, 2001.

SEN, Amartya. Desarrollo y libertad. Madrid: Planeta, 2000.

SUAREZ, Ana Lourdes; GIORGI, Guido; LEVITA, Gabriel. Estructura social y religión. Sexo. In: MALLIMACI, Fortunato. Atlas de las creencias religiosas en la Argentina. Buenos Aires: Biblos, p.146-154, 2013.

SUAREZ, Ana Lourdes; LOPEZ FIDANZA, Juan Martín. El campo religioso argentino hoy: creencia, autoadscripción y práctica religiosa. Una aproximación a través de datos agregados. In: Cultura y Religión. Revista de Sociedades en Transición. v. 7, n. 1. (2013) Dossier: La Diversidad Religiosa en Argentina, p. 98-115, 2013.

Debates do NER, Porto Alegre, Ano I5, N. 25, P. 24I-270, JAn./Jun. 20 I4 
VOAS, David. Surveys of Behaviour, Beliefs and Affiliation: Micro-Quantitative. In: The SAGE Handbook of the Sociology of Religion, BECKFORD, James A.; DEMERATH, N. J. III. London: Sage, p. 144-188, 2007.

WYNARCZYK, Hilario; ORO, Ari Pedro. El pentecostalismo en America Latina. In: Religioni e Societá. Revista di scienza social della religione. Anno xxvii. n. 73, p. 24, Maggio-Agosto, 2012.

Recebido em: 08/01/2014

Aprovado em: 21/02/2014 